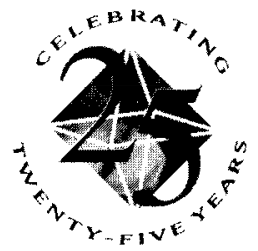

This year, the Materials Research Society celebrates its 25th anniversary. We all owe a great deal of thanks to the founders of the Society and everyone who has been involved with MRS over this past quarter-century.

As materials science has become more recognized as a distinct discipline, materials research has become a door to new areas, bringing together many disciplines. I firmly believe, as I'm sure many of you do, that MRS has played a key role in this development.

Some aspects of MRS are timeless. Our meetings, publications, and other activities offer scientists throughout the world a forum for discussions of materials research. At every turn, we see researchers excited about discoveries, inventions, and advancements. Their excitement is both in reporting to their colleagues and in learning of their colleagues' achievements.

These words-discovery, invention, and advancements-are some of my favorites about research, but it is all of us who are actually involved. I hope I can share some of my thoughts about the people of MRS. Maybe some of these instances will sound familiar to you: Have you ever sat in a

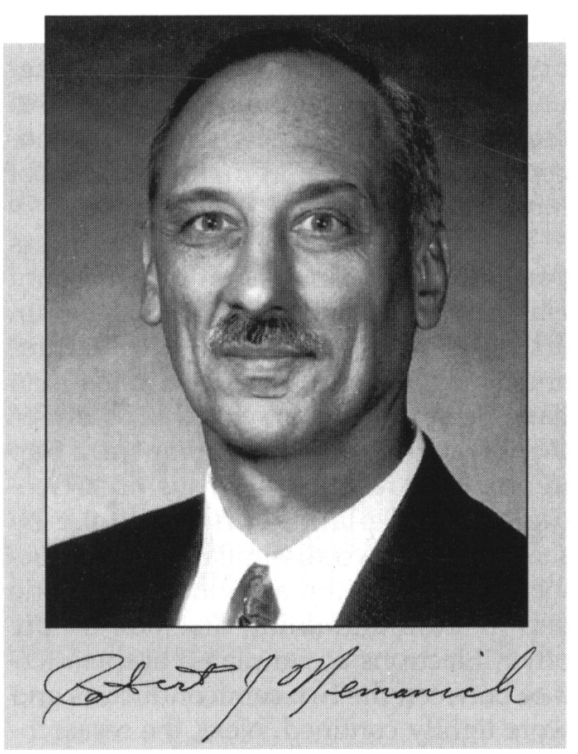

symposium and watched as researchers whom we all admire are clearly nervous about their presentations? It is usually evident at the beginning of their presentations; sometimes it's a crack in the voice, a fumbling of viewgraphs, or just that uncomfortable look. I find it often occurs when researchers are most excited about their achievements. Have you ever watched a group of researchers in the halls having a candid discussion? I often have seen one member draw a graph in "thin air" to try to describe some trend. It is really great to then see the others pointing into the same "thin air" to question some aspect of the trend. Have you ever walked into a poster session and had a hard time talking because of all of the excited discussions around you? I am always amazed that meeting attendees are eager at 8:30 in the morning for the first presentations to begin and are still carrying on challenging discussions at 11:00 p.m. in the MRS poster sessions.

While I can't predict the MRS of the future, I am confident that the future MRS will provide an even better forum for committed materials researchers to join together to report, challenge, and celebrate the discoveries, inventions, and advancements of all of their colleagues.

I invite you to celebrate the spirit of achievement in materials research that has been fostered in this 25 years of the Materials Research Society.

BOB NEMANICH

\title{
GET CONNECTED
}

\section{BENEFITS OF MEMBERSHIP}

\section{Two Annual MRs Meetings}

As an MRS member, you'll automatically receive the Call for Papers and Program for upcoming meetings, as well as discounted MRS Meeting registration rates.

\section{MRS Bulletin}

The MRS Bulletin is your free monthly publication with timely news and features on the research and development of advanced materials.

\section{Journal of Materials Research}

Yours for a very low member rate, Journal of Materials Research is an international archival journal encompassing physical, chemical, and engineering research on advanced materials and processing techniques.

\section{MRS Books \& Videotapes}

As an MRS member, you may purchase MRS books and videotapes at $15-30 \%$ below list price. You'll also enjoy reduced rates for journals and books from other scientific publishers.

\section{Opportunities to Connect}

- Career services for members include the Job Center at MRS Spring and Fall Meetings.

- The annual Membership Directory is your connection to over 12,400 MRS members worldwide.

- Reduced membership renewal and meeting fees are available to unemployed or retired members, as well as recent graduates as yet unemployed.
The strength of MRS continues to be its membersand its ability to link its members-with connections in academia, industry, and government.

Get connected to the MRS interdisciplinary scientific community. Submit your membership application today!

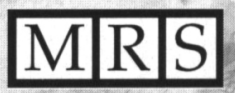

\section{FOR MORE INFORMATION}

Member Services

MATERIALS RESEARCH SOCIETY

506 Keystone Drive, Warrendale, PA 15086, USA

Telephone: 724-779-3003

Facsimile: $724-779-8313$

E-mail: info@mrs.org

Web site: http://www.mrs.org/ 